\title{
Blood pressure and anthropometry in children treated with stimulants: a longitudinal cohort study with an individual approach
}

This article was published in the following Dove Press journal:

Neuropsychiatric Disease and Treatment

16 February 2017

Number of times this article has been viewed

\author{
Magnus Landgren ${ }^{1,2}$ \\ Salmir Nasic ${ }^{3}$ \\ Mats Johnson ${ }^{1,2}$ \\ Trygve Lövoll' \\ Daniel Holmgren ${ }^{4,5}$ \\ Elisabeth Fernell ${ }^{2}$ \\ 'Department of Pediatrics, Unit of \\ Developmental Disorders, Skaraborg's \\ Hospital, Mariestad, ${ }^{2}$ Gillberg \\ Neuropsychiatry Centre, University \\ of Gothenburg, Gothenburg, \\ ${ }^{3}$ Research and Development Centre, \\ ${ }^{4}$ Department of Pediatrics, Skaraborg's \\ Hospital, Skövde, ${ }^{5}$ University of \\ Gothenburg, Gothenburg, Sweden
}

Correspondence: Magnus Landgren Department of Pediatrics, Unit of Developmental Disorders, Skaraborg's Hospital, Lockerudsvagen I2, 54224

Mariestad, Sweden

Tel +4650l 62575

Email magnus.landgren@vgregion.se
Background: Knowledge about the long-term effects on blood pressure (BP) and body mass index (BMI) when treating young patients for attention-deficit/hyperactivity disorder (AD/HD) with stimulants is limited. Most of the studies have reported mean and not individual values for anthropometrics and BP in treatment with stimulants. This seems to be the first study of changes based on the analyses of individual data measured over time.

Patients and methods: Seventy young patients (aged 8-18 years) diagnosed with AD/HD and responding well to treatment with stimulants were followed for a mean period of 3 years and 3 months. BP, heart rate, height, weight, and BMI were transformed to standard deviations or $z$-scores from before treatment to the last registered visit.

Results: The mean dose of methylphenidate was $0.95 \mathrm{mg} / \mathrm{kg}$. The mean increase of systolic and diastolic BP was $0.4 z$-score and $0.1 z$-score, respectively. The systolic BP was associated with BMI; a higher BMI at baseline increased the risk for an increase in systolic BP. Ten percent of the total group had a weight at follow-up of $<-1.5$ standard deviation (SD) and $12 \%$ had a height of $<-1.5 \mathrm{SD}$. Mean height at follow-up was $-0.2 \mathrm{SD}$, but $40 \%$ had a reduced height of at least $0.5 \mathrm{SD}$ during the treatment period. BMI on a group level was reduced from +0.8 $\mathrm{SD}$ to $+0.3 \mathrm{SD}$. Of the 19 patients with a $\mathrm{BMI}>+1.5 \mathrm{SD}$ at baseline, $50 \%$ had a significantly reduced BMI.

Conclusion: Consequences of stimulant treatment must be evaluated individually. Besides significant effects on core $\mathrm{AD} / \mathrm{HD}$ symptoms, some patients have lower BMI and BP and some increase/maintain their BMI and/or increase their systolic BP. The risk of reduced height trajectory needs further research.

Keywords: $\mathrm{AD} / \mathrm{HD}$, treatment, heart rate, long-term follow-up, methylphenidate, improvement, cardiovascular, overweight, height, BMI, health

\section{Introduction}

Attention-deficit/hyperactivity disorder (AD/HD) is the single most prevalent developmental disorder with a worldwide pooled prevalence of $\sim 5 \%$. ${ }^{1}$ The cognitive deficits that characterize $\mathrm{AD} / \mathrm{HD}$, that is, the executive dysfunctions, entail substantial problems for academic achievement and other social contexts. ${ }^{2}$ In individuals with $\mathrm{AD} / \mathrm{HD}$, there are increased risks for severe social problems, accidents, and substance abuse. ${ }^{3,4}$ In addition to the core symptoms of AD/HD, associated symptoms and disorders considerably affect the child's functioning and outcome..$^{5-7}$

Treatment involves counseling, educational interventions, parental support, and, for many, also medication. ${ }^{8-10}$ Stimulants, amphetamine and methylphenidate, have been used in Sweden since the 1990s, ${ }^{11}$ whereas in other parts of the world treatment 
started much earlier; $>70$ years ago with d,1-amphetamine (for a review, see Findling, 2008). ${ }^{12}$

Guidelines provide recent information in the fields of neuroimaging, neuropsychology, genetics, diagnostics, role of comorbidities, and consensus recommendations for the pharmacological treatment of AD/HD. Stimulants are effective drugs, and meta-analyses investigating their use have led to recommending their use as part of a comprehensive program..$^{910,13}$ In a recent bibliographic search of several databases, prospective studies evaluating the incidence of adverse events in children and adolescents treated pharmacologically for $\mathrm{AD} / \mathrm{HD}$ were reviewed. ${ }^{14}$ Treatment periods varied between 1 and 4 years. The rate of treatment-related adverse events ranged from $58 \%$ to $78 \%$; decreased appetite, insomnia, headache, and abdominal pain were the most common. The authors concluded that few studies evaluated the long-term safety of drugs for $\mathrm{AD} / \mathrm{HD}$ and that systematic monitoring of long-term safety is needed.

Pharmacological long-term intervention is considered safe with no evidence of increased risk for serious cardiovascular events such as sudden cardiac death, acute myocardial infarction, or stroke..$^{15}$ There are, however, some controversies with respect to parameters such as blood pressure (BP) and heart rate. In the Multimodal Treatment Study of Children with AD/HD (MTA study), the association between stimulant medication and BP and heart rate over 10 years was evaluated. ${ }^{16}$ No treatment effect on either systolic or diastolic BP could be detected but children treated with stimulants had a higher heart rate at the end of a 14-month controlled trial, but not thereafter. It was concluded from the study that stimulant treatment did not increase the risk for prehypertension or hypertension over the 10-year period of observation.

In the same MTA study, the effect of stimulant medication on physical growth was evaluated. It was found that at baseline, on a group level, the children had been taller than expected from norms but had shown stimulant-related decreases in growth rates after the initiation of treatment, which appeared to reach asymptotes within 3 years without evidence of growth rebound. ${ }^{17}$ Biederman et al found no evidence that $\mathrm{AD} / \mathrm{HD}$ was associated with adverse trajectories of height over time or differences at follow-up in any growth outcomes. ${ }^{18}$ Faraone et al analyzed longitudinal studies about deficits in expected growth among children with $\mathrm{AD} / \mathrm{HD}$ who had been treated with stimulants and with a follow-up of at least 1 year. ${ }^{19}$ They found that treatment with stimulant medication led to statistically significant delays in height and weight, but these deficits attenuated over time. Their review suggested that growth deficits may be dose dependent, that treatment cessation may lead to normalization of growth, and that further research should assess the idea that $\mathrm{AD} / \mathrm{HD}$ itself may be associated with dysregulated growth.

Our pediatric unit serves a county-based population of children and adolescents with $\mathrm{AD} / \mathrm{HD}$ and receives referrals for initiating pharmacological treatment. The children are followed regularly at the same clinic as long as treatment is sustained or up to the age of 18 years. The aim of this study was to evaluate long-term consequences, when treated with methylphenidate, for $\mathrm{BP}$, heart rate, weight, height, and body mass index (BMI).

\section{Patients and methods}

The catchment area of the study was the 15 municipalities served by Skaraborg's Hospital in southwestern Sweden (total population $\sim 300,000$ inhabitants). In this area, there is one specialized pediatric unit for pharmacological treatment of children and adolescents with ADHD.

At the time of start of the study, $\sim 200$ children and adolescents had their follow-up at this unit. The neurodevelopmental team at the unit comprises child neurologists, a pediatric nurse, a special education teacher, and a neuropsychologist.

All children had been referred to the team due to a suspicion of $\mathrm{AD} / \mathrm{HD}$ and for assessments with regard to pharmacological treatment. Medication in children is subsidized in Sweden and therefore available for everybody when needed. AD/HD was diagnosed according to the Diagnostic and Statistical Manual of Mental Disorders, 4th Edition (DSM-IV). Inclusion criteria were 1) pharmacological treatment for $\mathrm{AD} / \mathrm{HD}$, consistently for at least 1 year, 2) treatment with methylphenidate, and 3) a clinical global impression of severity corresponding to a significant impairment (Clinical Global Impression-Severity [CGI-S] level 5 or more) before starting pharmacological treatment. Exclusion criteria were co-existing intellectual disability and autism spectrum disorder and treatment with atomoxetine. No patient had a major chronic comorbidity such as epilepsy, a specific genetic syndrome, diabetes, or a severe respiratory or cardiovascular disorder. When the study started, Lis-dexamphetamine was not available in Sweden. At the beginning of the study, 100 individuals met the inclusion criteria. Because of limited resources, 70 patients were included. Some results are based on 67 participants because of missing data at baseline or at follow-up. The records of these participants were collected consecutively and reviewed without any selection.

A retrospective review of the records was performed and data on BP (mmHg), heart rate (beats per minute, bpm), height $(\mathrm{cm})$, weight $(\mathrm{kg})$, BMI $\left(\mathrm{kg} / \mathrm{m}^{2}\right)$, and an evaluation 
of clinical global impairment and improvement according to the CGI-S and Clinical Global Impression-Improvement (CGI-I) scales were recorded. ${ }^{20-22}$ Baseline characteristics of the participants are presented in Table 1. A prerequisite for pharmacological treatment was a significant functional impairment in all areas of functioning. In order to maintain a continuous medication, a significant reduction of symptoms and increase in level of functioning were required.

BP and heart rate and anthropometric data had been monitored every third month by the same pediatric nurse and every second time the measurement was followed by a visit to the pediatrician. BP and heart rate were obtained after sitting for $5 \mathrm{~min}$ in the nurse office, measured in the right arm using a cuff of adequate size for the patient's arm. Heart rate (bpm) was measured by palpation of the pulse at the child's wrist. If the measured level was above normal HR $>100$, systolic pressure $>120 \mathrm{mmHg}$, and diastolic $>80 \mathrm{mmHg}$, the measurements were repeated. Anthropometric measurements such as weight and height were measured by the nurse at the clinic using a calibrated scale and a ruler attached to the wall. Values were then transferred to growth charts in the computer-based record.

$\mathrm{BP}$ was calculated and presented as $z$-scores and percentiles according to recommendations by USA/ARS Children's Nutrition Research Centre, Baylor College of Medicine, BCM, Body Composition Laboratory (https://www.bcm. edu/bodycomplab/). ${ }^{23}$ The method takes into account age, gender, and height. The procedure was carried out by two pediatricians. Variables for BP, heart rate, height, weight, and BMI were registered and transformed to standard deviations, percentiles, or $z$-scores, measuring divergence from gender- and age-specific norms, from before treatment to the last registered visit. Descriptive statistics as mean and

Table I Baseline characteristics of participants in longitudinal study $(\mathrm{n}=70)$

\begin{tabular}{lll}
\hline Variables & Mean (SD) & Min-max \\
\hline Age (years) & $12.3(2.4)$ & $8-17$ \\
Treatment time (months) & $39.7(19.5)$ & $12-116$ \\
Methylphenidate (mg/kg) & $0.9(0.4)$ & $0.35-2.60$ \\
Systolic BP (mmHg) & $109(10)$ & $90-140$ \\
Diastolic BP (mmHg) & $63(7)$ & $43-80$ \\
Systolic BP (percentiles) & $51(25)$ & $5.8-98.5$ \\
Diastolic BP (percentiles) & $50(18)$ & $4.7-86.0$ \\
Heart rate (beats per minute) & $70.3(10.2)$ & $50-95$ \\
BMI (kg/m ${ }^{2}$ ) in SD & $0.8(1.4)$ & $-2.7-3.5$ \\
& $\mathbf{n}(\%)$ & \\
Girls & $9(12.9)$ & \\
Boys & $61(87.1)$ & \\
\hline
\end{tabular}

Abbreviations: SD, standard deviation; BP, blood pressure; BMI, body mass index min, minimum; max, maximum. percentages were presented. In order to explore factors associated with BP rise between baseline and follow-up, we have constructed a binary outcome variable (yes/no) for rise with respect to systolic and diastolic BP, respectively. We then analyzed factors that could be associated with a rise of systolic and diastolic BP in two separate logistic regression models. Data were analyzed using IBM Statistical Package for the Social Sciences (SPSS) statistics version 22.0 (IBM Corporation, Armonk, NY, USA). A $P$-value $<0.05$ was considered as statistically significant.

The study was approved by the Regional Ethical Review Board, Gothenburg, which advised that no patient consent was required. The limited data that were accessed at regular follow-up were transferred anonymously to a research data set.

\section{Results}

At inclusion, first visit/baseline, there were 61 boys and 9 girls with a mean age of 12 years, standard deviation (SD) 2.4 (range 8-17 years). Mean age at follow-up was 16 years (range $9-18$ years), and $80 \%$ had reported a significant improvement according to CGI-I. The mean dose of long-acting methylphenidate was $0.95 \mathrm{mg} / \mathrm{kg} /$ day (range $0.4-2.6 \mathrm{mg} / \mathrm{kg}$ ) at last visit. Some patients had two daily doses of methylphenidate. Average treatment length was 3 years and 3 months (3:3 years) (range 1:7-9:6 years). Measurements were compared to gender-specific norms, and splitting the analyses into female/male did not reveal any difference.

\section{Systolic BP}

At baseline, systolic mean BP was $+0.1 z$, and the mean percentile was 51. Mean systolic BP at follow-up was $+0.4 z$, and the mean percentile was 64 (Figure 1). At baseline, 33 of 67 $(49 \%)$ individuals with recorded BP measurements had a systolic BP below the 50th percentile. Of these, one-third $(n=12)$ remained below the 50th percentile during the treatment period and two-thirds $(n=21)$ increased above. Thirty-four individuals (51\%) started with a systolic BP above the 50th percentile, seven of these $(21 \%)$ decreased below the 50th percentile and 27 (79\%) remained above (Figure 1). Six (9\%) of the 67 individuals had a BP above the 90th percentile before treatment start. The systolic BP for five of these six fell below the 90th percentile during treatment. Six out of the 61 individuals $(10 \%)$ below the 90 th percentile at baseline increased above the 90th percentile at follow-up (Figure 1).

\section{Diastolic BP}

Mean diastolic BP was $+0.01 z$ and the percentile 50 at baseline. At follow-up, mean diastolic BP was $0.1 z$ and the percentile 54. Figure 2 illustrates that 34 (51\%) of the 


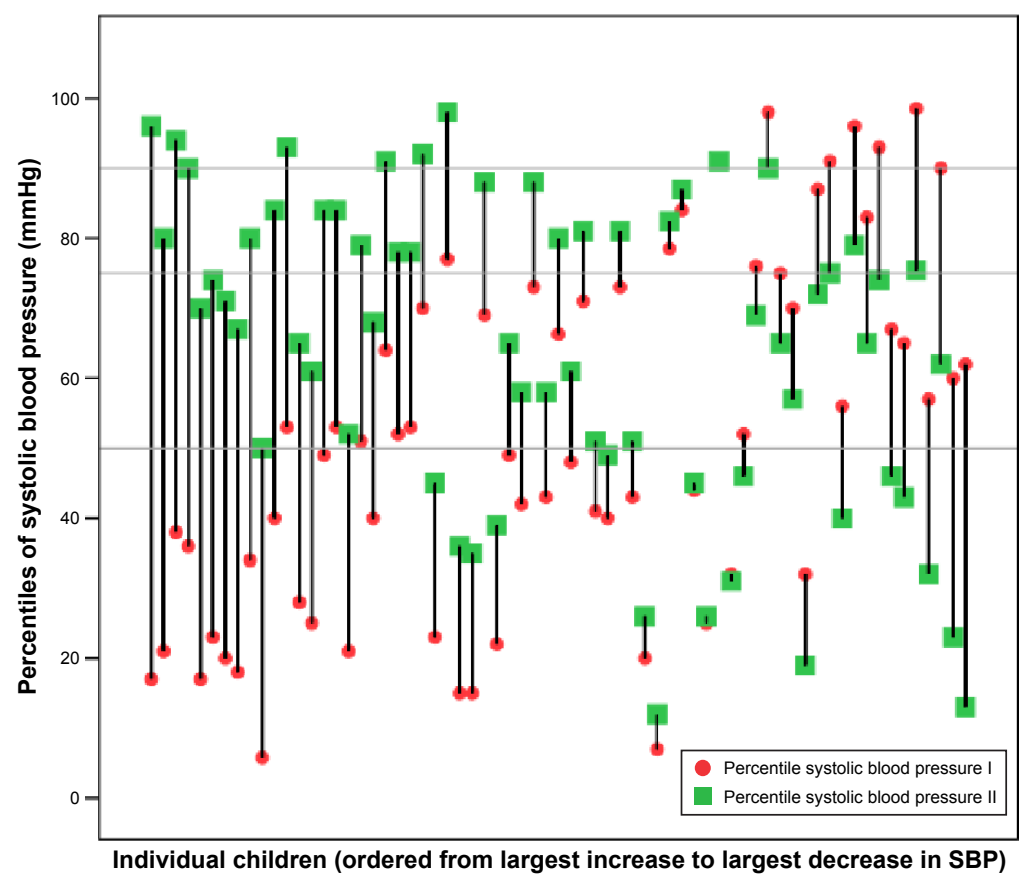

Figure I Changes in systolic blood pressure values, based on norm-population data, from baseline (I) to follow-up (II) expressed as percentiles, sorted in order from largest increase to largest decrease. The horizontal lines are references for median, 75th, and 90th percentile.

Abbreviation: SBP, systolic blood pressure.

67 individuals at baseline had a diastolic BP below the 50th percentile. Of the 34 with diastolic BP below the 50th percentile, $14(41 \%)$ increased and $20(59 \%)$ remained in the same category. Of the 33 with a diastolic BP above the 50th percentile, eight (24\%) decreased and 25 (76\%) remained. No child had a diastolic BP above the 90th percentile.

\section{$\mathrm{BP}$ and influence of BMI and dose of methylphenidate}

A logistic regression model with increase in systolic BP as outcome included gender, age, and dose of methylphenidate categorized into $<0.9 \mathrm{mg} / \mathrm{kg}$ or $\geq 0.9 \mathrm{mg} / \mathrm{kg}$, length of treatment, baseline BMI and BP. Only a higher BMI

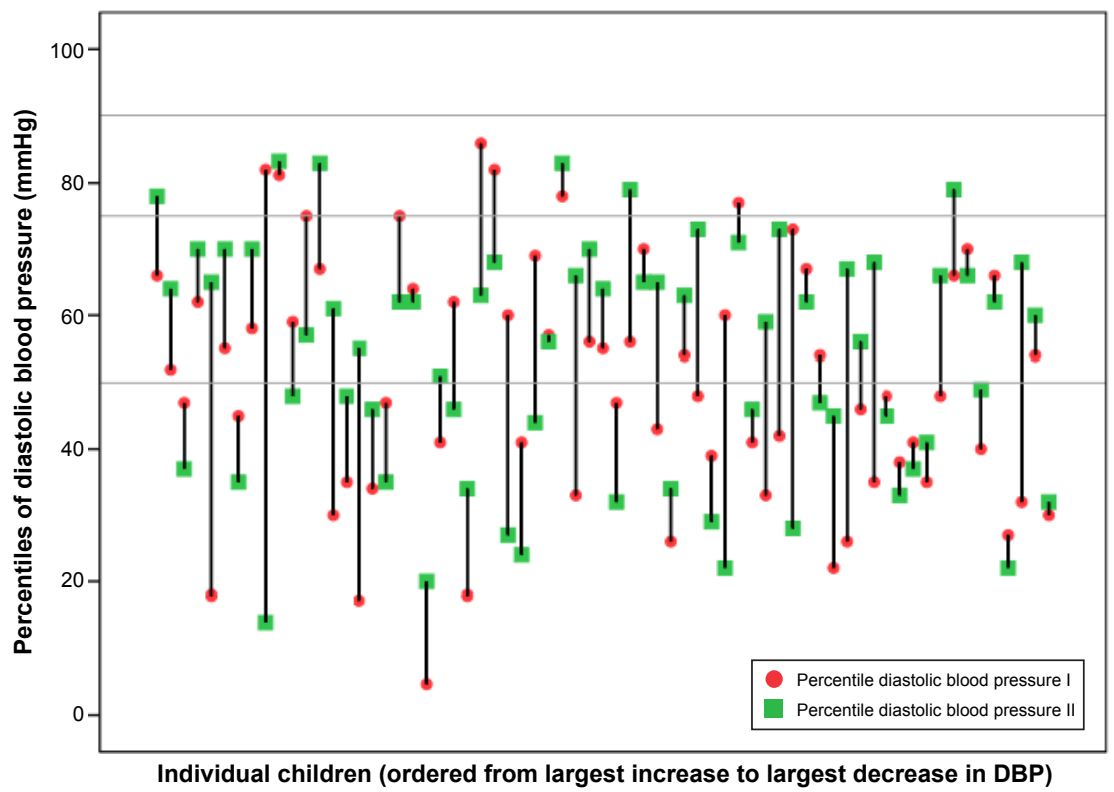

Figure 2 Diastolic BT expressed in percentiles related to normal population. Baseline (I) and follow-up (II). The horizontal lines are references for median, 75th, and 90 th percentile.

Abbreviation: DBP, diastolic blood pressure. 
at baseline increased the risk for an increase in systolic BP OR $=1.76(95 \%$ confidence interval [CI] 1.10-2.81; $P=0.02$ ). There was a significant correlation between BMI at baseline and increase in systolic BP $(r=0.53, P<0.001)$. The same model applied for diastolic BP revealed that dose $\geq 0.9 \mathrm{mg} / \mathrm{kg}$ entailed a higher risk for an increase in diastolic BP (OR 5.1; 95\% CI 1.36-19.65, $P=0.02$ ). There was a weak correlation between diastolic BP and BMI ( $r=0.24, P=0.04)$.

On a group level, there was no correlation between dose and systolic or diastolic BP as continuous variables.

\section{Heart rate}

Mean heart rate at baseline was 70 (median 68, range 50-95) and at follow-up 75 (median 72.5, range 60-98), $P=0.01$. There was a correlation at follow-up between heart rate and systolic BP ( $r=0.391, P=0.001)$ but not at baseline.

\section{Height}

At baseline, mean height was +0.1 SD. Mean height at follow-up was $-0.2 \mathrm{SD}$. Figure $3 \mathrm{~A}$ illustrates that 28 out of $69(41 \%)$ individuals deviated and decreased at least $0.5 \mathrm{SD}$ during the treatment period. Five (7\%) individuals had a height $\leq-1.5 \mathrm{SD}$ at baseline, and at follow-up, eight $(12 \%)$ had a height below $-1.5 \mathrm{SD}$. In a regression model that included age at treatment start, duration of treatment, gender, weight, and height at baseline and dose, only height at baseline had significant influence on height at follow-up $(P=0.04)$. There was a correlation between height at baseline and follow-up $(r=0.8, P<0.001)$. The group that decreased their height between baseline and follow-up was on average taller at baseline (median +0.25 $\mathrm{SD}$ vs $-0.4 \mathrm{SD}, P=0.01)$.

\section{Weight}

Mean weight at baseline and follow-up were $+0.9 \mathrm{SD}$ and +0.3 $\mathrm{SD}$, respectively. There was a correlation between dose and weight loss between baseline and follow-up ( $r=-0.3$, $P=0.01)$. Figure 3B illustrates that four out of 69 individuals $(6 \%)$ had a baseline weight $<-1.5 \mathrm{SD}$ and $24(34 \%)$ had a weight $>1.5 \mathrm{SD}$. At follow-up, seven (10\%) had a weight $<-1.5 \mathrm{SD}$ and $15(22 \%)$ had a weight $>1.5 \mathrm{SD}$.

\section{BMI}

Mean BMI at baseline and follow up were $+0.8 \mathrm{SD}$ and +0.3 $\mathrm{SD}$, respectively. Figure 4 depicts that 47 (68\%) had a reduced BMI during the treatment period, three remained the same and $18(26 \%)$ had an increased BMI. Of 22 individuals with baseline $\mathrm{BMI}< \pm 0 \mathrm{SD}, 21$ remained in that interval and one had an increase in BMI. Regarding the nine $<-1.5 \mathrm{SD}$ at follow-up, three were remaining from baseline and 6 were new. Of the 28 individuals with a baseline BMI between 0 and +1.5 SD, 10 had a lower BMI at follow-up, six had a higher BMI and 12 remained at their baseline BMI. Of the 19 individuals with a $\mathrm{BMI}>+1.5 \mathrm{SD}$ at baseline, $\sim 50 \%$ (10 individuals) still had the same BMI and $\sim 50 \%$ (nine individuals) had reduced their BMI. The mean dose of methylphenidate in the group with a BMI $>+1.5$ and the group $<+1.5$ at follow-up were 1.0 and $0.9 \mathrm{mg} / \mathrm{kg} / \mathrm{day}$, respectively. There was a tendency to greater BMI decrease between baseline and follow-up with doses $\geq 0.9 \mathrm{mg} / \mathrm{kg}$ but not statistically significant.

\section{A}

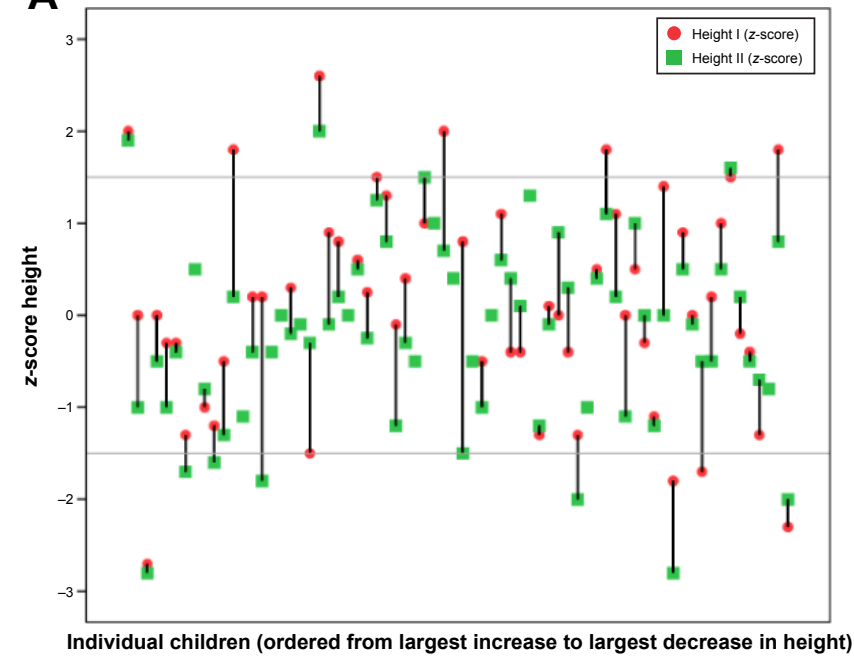

B

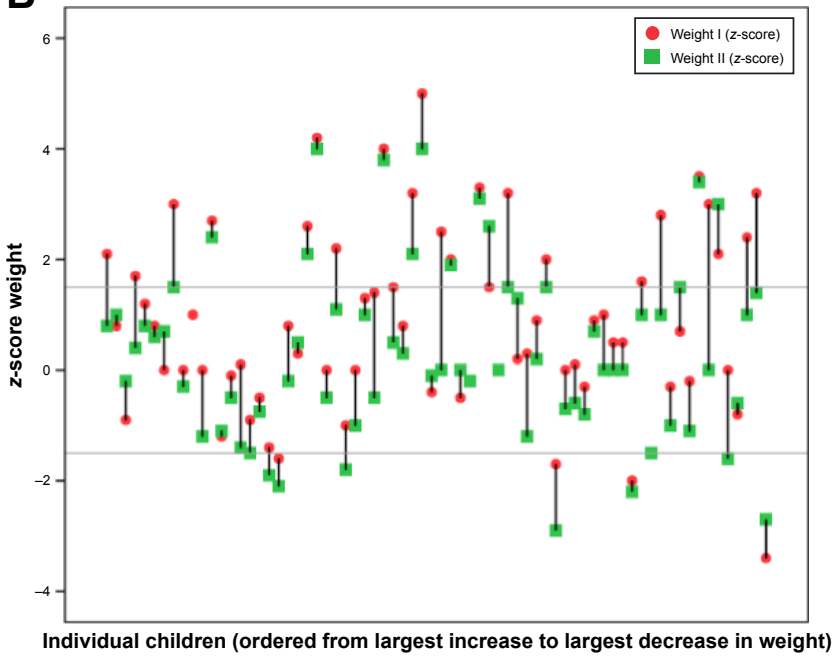

Figure 3 (A) Height and weight expressed as z-scores (individual deviation from mean for norms). Baseline (I) and follow-up (II). The horizontal lines are references for median, 75th, and 90th percentile. (B) Weight expressed as z-scores (individual deviation from mean for norms). Baseline (I) and follow-up (II). The horizontal lines are references for median, 75 th, and 90 th percentile. 


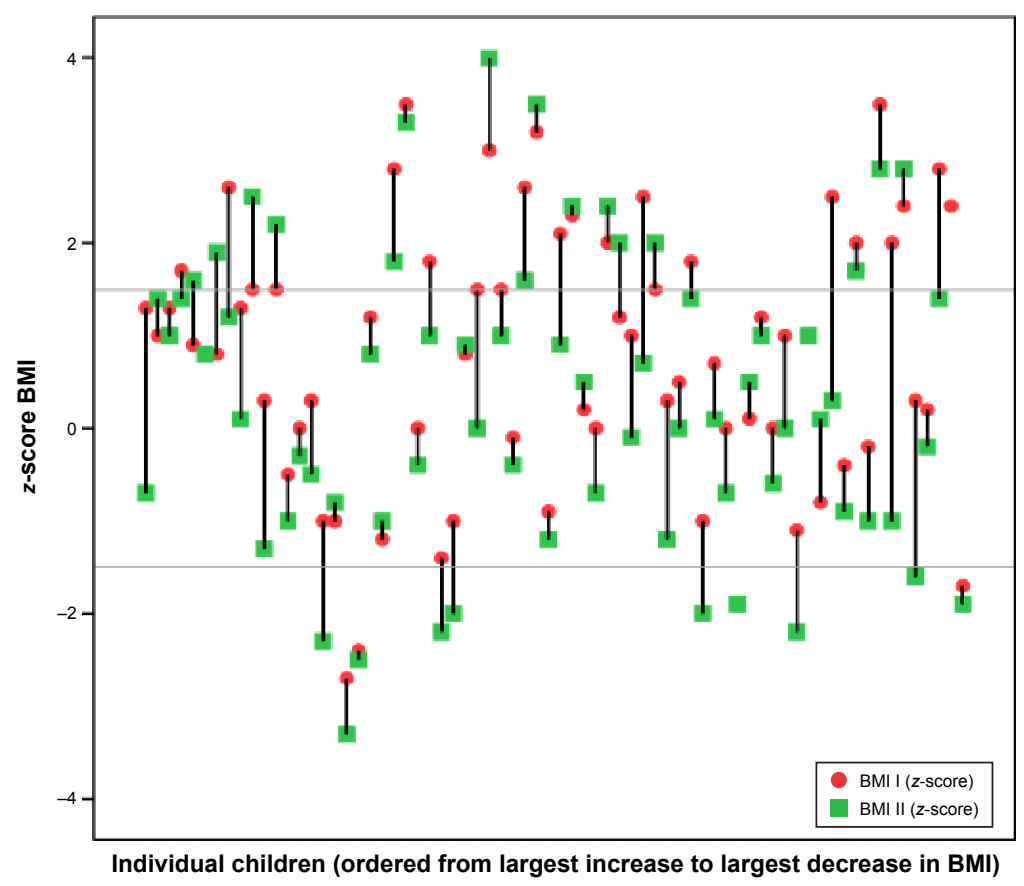

Figure 4 Body mass index (BMI) expressed as z-scores (individual deviation from mean for norms). Baseline (I) and follow-up (II). The horizontal lines are references for median, 75th, and 90th percentile.

\section{Discussion}

This is a longitudinal, clinically based study of the development of systolic and diastolic BP, heart rate, weight, height, and BMI over a mean of $>3$ years, range 1:7-9:6 years. The study group consisted of a representative clinical cohort of 70 patients, aged 8-18 years, treated with stimulants for $\mathrm{AD} / \mathrm{HD}$. Children with major comorbidities, such as autism and intellectual disability, had been excluded from the study, but the vast majority had at least one coexisting disorder, such as dyslexia, developmental coordination disorder, oppositional defiant disorder, or another of the commonly reported comorbidities in ADHD. ${ }^{5} \mathrm{BP}$, heart rate, and anthropometric data were analyzed both individually and on a group level. The follow-up was performed by the same team, and compliance to nurse/physicians visit four times a year was good. Baseline values for BP and height, but not weight accorded to population norms.

Systolic BP increased on a group level to $0.4 z$-score and diastolic pressure to $0.1 z$-score, but there was a significant individual variation with regard to changes in BP that should be considered. Of the six (10\%) individuals with pre-systolic hypertension (90th to 95th percentile) before treatment, five decreased below the 90th percentile and another five increased above the 90th percentile. In a regression model, systolic BP was also significantly associated with higher baseline BMI but not with methylphenidate dose. There has been a concern that stimulants add to the risk for later hypertension. Long-term follow-up is therefore important in order to understand the potential risk. Elevated BP is associated with coronary heart disease and stroke risk. ${ }^{24} \mathrm{An}$ increasing correlation with age, between childhood BP and hypertension in later life has been reported. ${ }^{25}$ Lower socioeconomic position and fetal programing, such as maternal experience of famine, low birth weight and smoking during pregnancy, are examples of independent associated and studied determinants of later increase in BP..$^{26-31}$

In children and adolescents, BP increases with age while heart rate decreases. The increase of heart rate over time and correlation between heart rate and systolic BP observed at follow-up, in the present study, indicate that the treatment, at least in some way, affected the cardiovascular system. ${ }^{20,24}$

Being overweight at baseline is both a risk factor for an increased systolic BP and an indication of possible beneficial side effects of treatment with stimulants, that is, weight reduction. Overall, BMI was reduced by $63 \%$, from $0.8 \mathrm{SD}$ to $0.3 \mathrm{SD}$, and $50 \%$ of the patients in the group who were overweight according to WHO standards were no longer overweight at follow-up. There is a growing awareness that overweight children are at risk for diseases common in adults. ${ }^{32,33}$ In this context, the link between $\mathrm{AD} / \mathrm{HD}$, obesity, and hypertension needs to be considered alongside long-term effect of stimulants on these variables. The additional health benefits in the reduction of BMI and systolic BP for lowering 
risk for the metabolic syndrome and cardiovascular disease are important both for the individual child and secondly for societal health and social costs.

The treatment effect on height development on a group level was $-0.2 \mathrm{SD}$, perhaps negligible but the group of children with height $<-1.5 \mathrm{SD}$ increased from $5 \%$ to $10 \%$. In $39 \%$ of the children, their relative height decreased by $0.5 \mathrm{SD}$ during the treatment period. This is a cause of concern and not fully studied in these subjects. Interpretation is limited in this aspect because of a lack of an unmedicated comparison group, lack of a systematic evaluation of prenatal factors, such as toxic exposures, and hereditary influences. Moreover, puberty was not considered in relation to treatment although age and gender were always accounted for according to population norms. The influence of weight on height trajectory is well known and may also be a factor of importance in our group.

Stimulant treatment and growth were studied in a longitudinal study from Rochester Epidemiology project, including 340 individuals with childhood AD/HD and 680 age- and gender-matched controls in the 1976-1982 birth cohort. Height-for-age $z$-scores at the beginning $(0.48)$ to end of treatment $(0.33)$ among the $\mathrm{AD} / \mathrm{HD}$ cases treated for $>3$ years approached statistical significance $(P=0.06)$, but the difference was considered clinically insignificant. The authors concluded that neither childhood AD/HD itself nor treatment with stimulants is associated with significant deficits in height into adulthood. ${ }^{34}$

The main limitations of our study include that the study group was relatively small, 70 patients, and that a within subjects design, with no comparison group, was used. Strengths of our study would be the clinical, representative group that could be followed systematically by the same team over several years (on average 3 years).

No detailed analysis of autonomic regulation was performed. Findings supporting an autonomic dysfunction in children with unmedicated ADHD have been reported. ${ }^{35}$ A study of pharmacologically untreated children with ADHD by Tonhajzerova et $\mathrm{al}^{36}$ revealed decreased cardiac vagal modulation and tachycardia in supine positions, with altered ability of dynamic activation of the autonomic nervous system in response to orthostasis, indicating changes in the cardiac autonomic regulation in this patient group. Another study, including a systematic review of the relationship between cardiac vagal control (CVC) and ADHD, has suggested that children with unmedicated ADHD experience dampened CVC reactivity during tasks involving self-regulation and emotion regulation and that medication acted to correct the autonomic imbalance, but did not bring the imbalance to normal levels. ${ }^{37}$ In our study group, measurements of BP and heart rate were performed in a well-known setting, which should reduce the risk of obtaining an elevated generalized sympathetic activity in the child.

Pharmacological treatment of children and adolescents call for careful and individualized consideration of both prognosis of $\mathrm{AD} / \mathrm{HD}$ and risks for cardiovascular disease and the metabolic syndrome in adult life. It is important to consider $\mathrm{AD} / \mathrm{HD}$ as a spectrum disorder and a symptom expression with several etiologies. Neurodevelopmental disorders such as AD/HD, developmental coordination disorder and autism, are all strongly linked to both hereditary factors, toxic exposure during pregnancy such as alcohol and smoking as well as to prematurity, low birth weight, and other perinatal insults..$^{38-42}$

According to recommendations, BP and anthropometric parameters are regularly collected and monitored at follow-up in clinical practice but often only superficially evaluated. However, this study adds to the understanding that pharmacological treatment of $\mathrm{AD} / \mathrm{HD}$ has to be considered individually with a view to improving functioning and to consider potential adverse effects. To achieve this, a holistic perspective, including growth and development, should be applied with pediatricians and child psychiatrists.

\section{Disclosure}

The authors report no conflicts of interest in this work.

\section{References}

1. Polanczyk G, de Lima MS, Horta BL, Biederman J, Rohde LA. The worldwide prevalence of ADHD: a systematic review and metaregression analysis. Am J Psychiatry. 2007;164:942-948.

2. Chiang HL, Gau SS. Impact of executive functions on school and peer functions in youths with ADHD. Res Dev Disabil. 2014;35: 963-972.

3. Shilon Y, Pollak Y, Aran A, Shaked S, Gross-Tsur V. Accidental injuries are more common in children with attention deficit hyperactivity disorder compared with their non-affected siblings. Child Care Health Dev. 2012;38:366-370.

4. Harty SC, Galanopoulos S, Newcorn JH, Halperin JM. Delinquency, aggression, and attention-related problem behaviors differentially predict adolescent substance use in individuals diagnosed with ADHD. Am J Addict. 2013;22:543-550.

5. Kadesjö B, Gillberg C. The comorbidity of ADHD in the general population of Swedish school-age children. J Child Psychol Psychiatry. 2001;42:487-492.

6. Cherkasova M, Sulla EM, Dalena KL, Pondé MP, Hechtman L. Developmental course of attention deficit hyperactivity disorder and its predictors. J Can Acad Child Adolesc Psychiatry. 2013;22:47-54.

7. Dalsgaard S, Mortensen PB, Frydenberg M, Thomsen PH. Long-term criminal outcome of children with attention deficit hyperactivity disorder. Crim Behav Ment Health. 2013;23:86-98.

8. Greenhill LL, Pliszka S, Dulcan MK, et al. Practice parameter for the use of stimulant medications in the treatment of children, adolescents, and adults. American Academy of Child and Adolescent Psychiatry. $J$ Am Acad Child Adolesc Psychiatry. 2002;41:26S-49S. 
9. Wolraich M, Brown L, Brown RT, et al. Subcommittee on AttentionDeficit/Hyperactivity Disorder; Steering Committee on Quality Improvement and Management. ADHD: clinical practice guideline for the diagnosis, evaluation, and treatment of attention-deficit/hyperactivity disorder in children and adolescents. Pediatrics. 2011;128:1007-1022.

10. Bolea-Alamañac B, Nutt DJ, Adamou M, et al. British Association for Psychopharmacology. Evidence-based guidelines for the pharmacological management of attention deficit hyperactivity disorder: update on recommendations from the British Association for Psychopharmacology. J Psychopharmacol. 2014;28:179-203.

11. Gillberg C, Melander H, von Knorring AL, et al. Long-term stimulant treatment of children with attention-deficit hyperactivity disorder symptoms. A randomized, double-blind, placebo-controlled trial. Arch Gen Psychiatry. 1997;54:857-864.

12. Findling RL. Evolution of the treatment of attention-deficit/hyperactivity disorder in children: a review. Clin Ther. 2008;30:942-957.

13. Banaschewski T, Coghill D, Santosh P, et al. Long-acting medications for the treatment of hyperkinetic disorders - a systematic review and European treatment guideline. Eur Child Adolesc Psychiatry. 2006; 15:476-495.

14. Clavenna A, Bonati M. Safety of medicines used for ADHD in children: a review of published prospective clinical trials. Arch Dis Child. 2014;99:866-872.

15. Cooper WO, Habel LA, Sox CM, et al. ADHD drugs and serious cardiovascular events in children and young adults. $N$ Engl J Med. 2011;365: 1896-1904.

16. Vitiello B, Elliott GR, Swanson JM, et al. Blood pressure and heart rate over 10 years in the multimodal treatment study of children with ADHD. Am J Psychiatry. 2012;169:167-177.

17. Swanson JM, Elliott GR, Greenhill LL, et al. Effects of stimulant medication on growth rates across 3 years in the MTA follow-up. J Am Acad Child Adolesc Psychiatry. 2007;46:1015-1027.

18. Biederman J, Spencer TJ, Monuteaux MC, Faraone SV. A naturalistic 10-year prospective study of height and weight in children with attention deficit hyperactivity disorder grown up: sex and treatment effects. J Pediatr. 2010;157:635-640.

19. Faraone SV, Biederman J, Morley CP, Spencer TJ. Effect of stimulants on height and weight: a review of the literature. J Am Acad Child Adolesc Psychiatry. 2008;47:994-1009.

20. Fleming S, Thomson M, Stevens R, et al. Normal ranges of heart rate and respiratory rate in children from birth to 18 years: a systematic review of observational studies. Lancet. 2011;377:1011-1018.

21. American Academy of Pediatrics. National High Blood Pressure Education Program Working Group on High Blood Pressure in Children and Adolescents. Pediatrics. 2004;114(Suppl 2):iv.

22. Busner J, Targum SD, Miller DS. The clinical global impressions scale: errors in understanding and use. Compr Psychiatry. 2009;50:257-262.

23. USA/ARS Children's Nutrition Research Centre, Baylor College of Medicine, BCM, Body Composition Laboratory. Available from: https://www.bcm.edu/bodycomplab/. Accessed August 2016.

24. Lewington S, Clarke R, Qizilbash N, Peto R, Collins R; Prospective Studies Collaboration. Age-specific relevance of usual blood pressure to vascular mortality: a meta-analysis of individual data for one million adults in 61 prospective studies. Lancet. 2002;360:1903-1913.
25. Chen $\mathrm{X}$, Wang Y. Tracking of blood pressure from childhood to adulthood a systematic review and meta-regression analysis. Circulation. 2008;117:3171-3180.

26. Lawlor DA, Smith GD. Early life determinants of adult blood pressure. Curr Opin Nephrol Hypertens. 2005;14:259-264.

27. Roseboom TJ, van der Meulen JH, Ravelli AC, et al. Blood pressure in adults after prenatal exposure to famine. J Hypertens. 1999;17: 325-330.

28. Winder NR, Krishnaveni GV, Hill JC, et al. Placental programming of blood pressure in Indian children. Acta Paediatr. 2011;100:653-660.

29. Eriksson J, Forsén T, Tuomilehto J, Osmond C, Barker D. Fetal and childhood growth and hypertension in adult life. Hypertension. 2000; 36:790-794.

30. Barker DJ, Osmond C, Simmonds SJ, Wield GA. The relation of small head circumference and thinness at birth to death from cardiovascular disease in adult life. BMJ. 1993;306:422-426.

31. Blake KV, Gurrin LC, Evans SF, et al. Maternal cigarette smoking during pregnancy, low birth weight and subsequent blood pressure in early childhood. Early Hum Dev. 2000;57:137-147.

32. Davis C. Attention-deficit/hyperactivity disorder: associations with overeating and obesity. Curr Psychiatry Rep. 2010;12:389-395.

33. Khalife N, Kantomaa M, Glover V, et al. Childhood attention-deficit/ hyperactivity disorder symptoms are risk factors for obesity and physical inactivity in adolescence. J Am Acad Child Adolesc Psychiatry. 2014; $53: 425-436$

34. Harstad EB, Weaver AL, Katusic SK, et al. ADHD, stimulant treatment, and growth: a longitudinal study. Pediatrics. 2014;134:e935-e944.

35. Rukmani MR, Seshadri SP, Thennarasu K, Raju TR, Sathyaprabha TN. Heart rate variability in children with attention-deficit/hyperactivity disorder: a pilot study. Ann Neurosci. 2016;23(2):81-88.

36. Tonhajzerova I, Ondrejka I, Adamik P, et al. Changes in the cardiac autonomic regulation in children with attention deficit hyperactivity disorder (ADHD). Indian J Med Res. 2009;130(1):44-50.

37. Rash JA, Aguirre-Camacho A. Attention-deficit hyperactivity disorder and cardiac vagal control: a systematic review. Atten Defic Hyperact Disord. 2012;4(4):167-177.

38. Sherman DK, McGue MK, Iacono WG. Twin concordance for attention deficit hyperactivity disorder: a comparison of teachers' and mothers' reports. Am J Psychiatry. 1997;154:532-535.

39. Levy F, Hay DA, McStephen M, Wood C, Waldman I. Attention-deficit hyperactivity disorder: a category or a continuum? Genetic analysis of a large-scale twin study. J Am Acad Child Adolesc Psychiatry. 1997;36: 737-744.

40. Landgren M, Kjellman B, Gillberg C. Attention deficit disorder with developmental coordination disorders. Arch Dis Child. 1998;79: 207-212.

41. Landgren M, Svensson L, Strömland K, Andersson Grönlund M. Prenatal alcohol exposure and neurodevelopmental disorders in children adopted from Eastern Europe. Pediatrics. 2010;125:e1178-e1185.

42. Lou HC. Etiology and pathogenesis of attention-deficit hyperactivity disorder (ADHD): significance of prematurity and perinatal hypoxichaemodynamic encephalopathy. Acta Paediatr. 1996;85:1266-1271.
Neuropsychiatric Disease and Treatment

\section{Publish your work in this journal}

Neuropsychiatric Disease and Treatment is an international, peerreviewed journal of clinical therapeutics and pharmacology focusing on concise rapid reporting of clinical or pre-clinical studies on a range of neuropsychiatric and neurological disorders. This journal is indexed on PubMed Central, the 'PsycINFO' database and CAS,

\section{Dovepress}

and is the official journal of The International Neuropsychiatric Association (INA). The manuscript management system is completely online and includes a very quick and fair peer-review system, which is all easy to use. Visit http://www.dovepress.com/testimonials.php to read real quotes from published authors. 